\title{
Long-term Potentiation Induces Synaptic Plasticity at Nontetanized Adjacent Synapses
}

\author{
Christine M. Coussens ${ }^{1}$ and Timothy J. Teyler ${ }^{2}$ \\ Department of Neurobiology \\ Northeastern Ohio College of Medicine \\ Rootstown, Ohio 44224
}

\begin{abstract}
The two forms of long-term potentiation (LTP) and one form of long-term depression (LTD) in hippocampal area CA1 are induced by different afferent tetani: LTD is induced by a 3- to 5-Hz tetanus, whereas higher frequencies are necessary for LTP mediated by NMDA receptors (25- to $50-\mathrm{Hz}$ tetanus) and LTP mediated by voltage-dependent calcium channels (200-Hz tetanus). It has been suggested that the three forms are induced by graded increases in postsynaptic calcium, with LTD being induced at the lowest calcium concentration. We hypothesized that synapses near a site of LTP induction would elicit LTD owing to diffusion of calcium or its binding proteins. This was tested using a fixed multistimulating electrode array spanning stratum radiatum in area CA1 of rat hippocampal slices. The tetanized sites all displayed LTP. Nontetanized sites displayed LTD following a 50-Hz tetanus, whereas LTD was often seen following a 200-Hz tetanus. In most instances pEPSP and population spike responses were similiar; however, EPSP/spike dissociations (LTD of EPSP, LTP of spike) were seen following activation of NMDA receptors by $50-\mathrm{Hz}$ and $200-\mathrm{Hz}$ tetani. The results are discussed with respect to mechanisms of action and functional significance.
\end{abstract}

\section{Introduction}

Area CA1 of the hippocampus exhibits three

'Present address: Department of Psychology, University of Otago, Dunedin, New Zealand.

${ }^{2}$ Corresponding author. forms of homosynaptic synaptic plasticity: longterm potentiation (LTP) induced by NMDA receptor activation (NMDALTP), LTP induced by activation of voltage-dependent calcium channels (vDCCLTP), and long-term depression (LTD) mediated by NMDA receptor activation (NMDALTD). These forms are homosynaptic, referring to the input specificity of the fibers and their synapses that have been activated by the stimulation (Teyler et al. 1994). However, others have reported instances of heterosynaptic LTP and LTD at synaptic sites not receiving tetanization (Abraham and Goddard 1983; Abraham and Wickens 1991 ).

All forms of synaptic plasticity are induced by postsynaptic increases in cytosolic $\mathrm{Ca}^{2+}$ and can be blocked by the intracellular application of $\mathrm{Ca}^{2+}$ chelators (Teyler et al. 1994). The form of synaptic plasticity expressed (LTP vs. LTD) is hypothesized to be a function of cytosolic calcium levels (Lisman 1989; Artola and Singer 1993) and compartmentalization of calcium-binding proteins (Teyler et al. 1994). Low postsynaptic $\mathrm{Ca}^{2+}$ levels are associated with LTD, whereas higher cytosolic $\mathrm{Ca}^{2+}$ levels are associated with LTP. The induction of LTP at one dendritic site increases postsynaptic $\mathrm{Ca}^{2+}$ levels locally and may influence adjacent sites as well. Thus, the induction of LTP at one dendritic location may be associated with LTD at adjacent synapses exposed to lower calcium levels or lower levels of calcium-binding proteins. We suggest that tetanic stimulation locally increases intracellular $\mathrm{Ca}^{2+}$ resulting in $\mathrm{a} \mathrm{Ca}^{2+}$ gradient along the length of the dendrite (Fig. 1). At the site of a $200-\mathrm{Hz}$ tetanus, both forms of LTP would be induced (NMDALTP and VDCCLTP) owing to the high levels of cytosolic $\mathrm{Ca}^{2+}$ resulting from the tetanus. Dendritic areas immediately adjacent would experience lower $\mathrm{Ca}^{2+}$ levels and would express NMDALTP; areas more distal still, where the $\mathrm{Ca}^{2+}$ concentration is even lower, would express

LEARNING \& MEMORY 3:106-114 (c) 1996 by Cold Spring Harbor Laboratory Press ISSN1072-0502/96 \$5.00

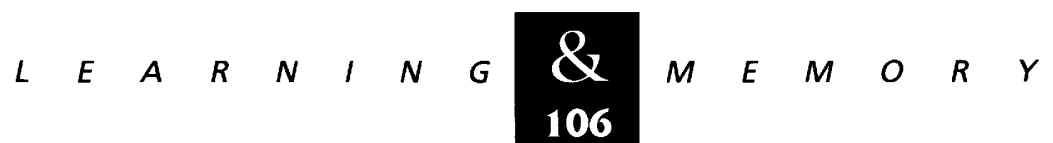




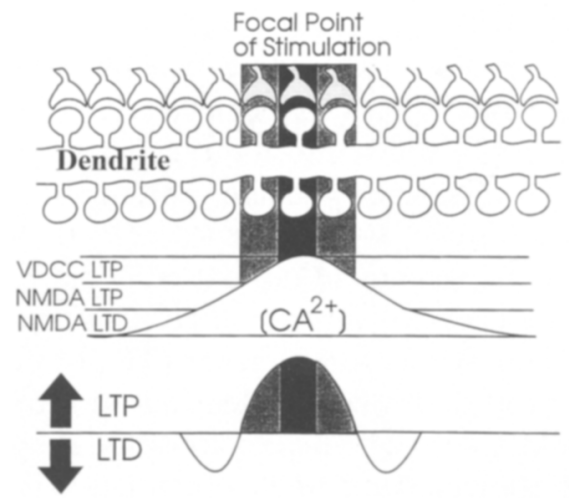

Figure 1: Cytosolic $\mathrm{Ca}^{2+}$ is central to determining the physiological response of the cell. The multiple plasticity model predicts that LTP induced at one dendritic locus may be accompanied by LTD at adjacent sites owing to diffusion of cytosolic $\mathrm{Ca}^{2+}$ or its binding proteins. Reproduced with permission from Teyler et al. (1994).

LTD. This hypothesis was tested using a multistimulating electrode situated in the dendritic layer of CA1.

\section{Materials and Methods}

Transverse hippocampal slices from LongEvans rats, 300 - to $400-\mu \mathrm{m}$ thick, were prepared as described previously ('Teyler 1980). Slices were placed in a humidified interface recording chamber at $32-33^{\circ} \mathrm{C}$, with an aCSF solution perfused continuously over the upper surface of the slice. The aCSF was bubbled continuously with a mixture of $95 \% \mathrm{O}_{2}$ and $5 \% \mathrm{CO}_{2}$. The composition of the aCSF was: $124 \mathrm{~mm} \mathrm{NaCl}, 3.35 \mathrm{~mm} \mathrm{KCl}, 1.25 \mathrm{~mm}$ $\mathrm{NaH}_{2} \mathrm{PO}_{4}, 2.0 \mathrm{~mm} \mathrm{CaCl}, 2.0 \mathrm{~mm} \mathrm{MgSO}_{4}, 10 \mathrm{~mm}$ dextrose, and $25 \mathrm{~mm} \mathrm{NaHCO}_{3}$.

The arrangement of recording and stimulating electrodes is depicted in Figure 2. A glass recording electrode filled with $2 \mathrm{~m} \mathrm{NaCl}(2-5 \mathrm{M} \Omega$ ) was placed just dorsal to stratum pyramidale to elicit a population EPSP (pEPSP) and population spike. A stimulating electrode array was placed vertically in stratum radiatum. The linear electrode array extended from the hippocampal fissure to stratum pyramidale. The attributes of the stimulating electrode array were described previously when it was used as a multirecording electrode (Borroni et al. 1991). Briefly, the electrodes are six $25-\mu \mathrm{m}$ diameter, insulated metal wires spaced $100 \mu \mathrm{m}$ between wires. Two adjacent wires constitute a bipolar stimulating electrode, with current provided by a Grass stimulator. Thus, electrode A consisted

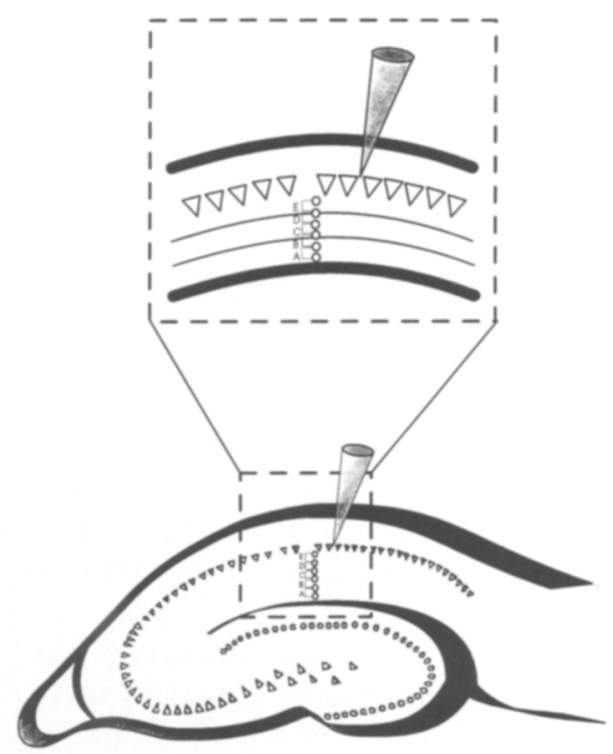

Figure 2: Schematic drawing of a hippocampal slice showing the location of the stimulating and recording electrodes in area CA1. The glass recording electrode was placed in stratum pyramidale. The stimulating electrodes were in a vertical array spanning the fibers of stratum radiatum from the fissure to the cell body layer.

of wires 1 and 2, electrode B consisted of wires 2 and 3, etc. The electrode array provided for five stimulating sites (A-E) and was not repositioned during the experiment. Relative to electrode C, electrodes $B$ and D are termed proximal; electrodes $A$ and $E$ are termed distal. Proximal electrodes $\mathrm{B}$ and $\mathrm{D}$ shared a common pole with electrode $\mathrm{C}$; thus, some fibers stimulated by electrodes $B$ and D overlapped with electrode C. Distal electrodes $\mathrm{A}$ and $\mathrm{E}$ were independent of electrode $\mathrm{C}$. All results are compared with baseline of the same electrode; thus, a depression is a decrease in the population spike or pEPSP from baseline levels of that electrode.

Baseline ( $1 / 60 \mathrm{sec})$ responses were obtained from the five stimulating electrodes, followed by a $50-\mathrm{Hz}$ (0.5-sec duration given seven times) or a 200-Hz (0.5-sec duration given seven times) tetanus delivered to electrode $C$. Post-tetanus responses were obtained ( $1 / 60 \mathrm{sec}$ ) from all electrodes at 20 min post-tetanus. Electrodes A, B, D, and $\mathrm{E}$ were never tetanized. The criteria for LTP induction were as follows: pEPSP $>110 \%$ of the baseline EPSP slope; population spike $>115 \%$ of the baseline amplitude. The criteria for LTD induction were pEPSP $<90 \%$ of the baseline slope and population spike $<85 \%$ of baseline amplitude. The pEPSP was quantified by measuring the maximal

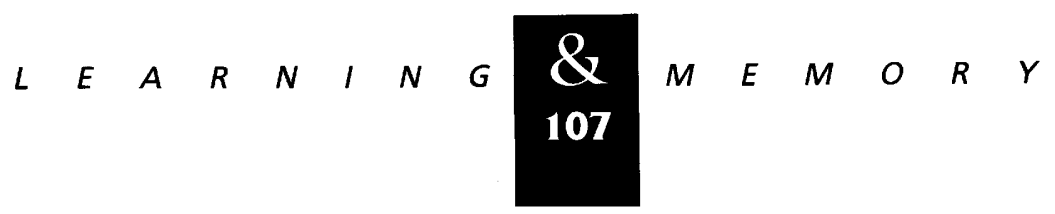


slope between the stimulus artifact and initiation of the population spike and expressing the posttetanus values as a percentage change with respect to the final $10 \mathrm{~min}$ of the pretetanus baseline period. In some experiments, $50 \mu \mathrm{M}$ APV (Sigma) or $5 \mu \mathrm{M}$ Nifedipine (Sigma) was added to the aCSF prior to the $200-\mathrm{Hz}$ tetanus to block NMDA-mediated responses and VDCC-mediated responses, respectively. Nifedipine was dissolved in DMSO to a final concentration of DMSO $<1 \%$. Control experiments $(n=3)$ indicated that this concentration of DMSO had no effect on baseline pEPSPs. Nifedipine and Bay K $8644(0.5 \mu \mathrm{M})$ experiments were conducted in a darkened room. DMSO vehicle alone was without effect.

After the post-tetanus responses were obtained, paired-pulse stimulation was used (120msec interpulse interval) to assess the degree of overlap of fibers activated by the different electrodes. The stimulation intensity was adjusted so the responses were approximately the same amplitude.

\section{Results}

\section{PAIRED-PULSE FACILITATION}

Because adjacent stimulation sites shared a common electrode pole, some fibers were activated by both electrodes. To assess this, pairedpulse facilitation was used to measure the degree of shared fiber activation by electrode $C$ and proximal electrodes B or D, and between electrode C and distal electrodes $\mathrm{A}$ or $\mathrm{E}$. As a point of comparison, the pEPSP slope was increased by $86.5 \%$ when the paired-pulse stimulation was delivered to the same electrode (C). For electrodes A, B, D and $\mathrm{E}$, the first pulse was given to electrode $\mathrm{C}$ followed by the second pulse to one of the other electrodes. As expected, the slope of the pEPSP of proximal electrodes B and D increased by $57.2 \%$ and $64 \%$, respectively, as these adjacent sites can be expected to have many fibers in common. The distal sites $A$ and $E$ showed only small changes in the pEPSP slope (electrode $\mathrm{A}=4.4 \%$, electrode $E=6.5 \%$ ), suggesting that few fibers are shared between electrode $\mathrm{C}$ and distal electrodes $\mathrm{A}$ and $\mathrm{E}$.

\section{LTP-DISTAL SITES-POPULATION SPIKE}

A 200-hz tetanus in normal aCSF delivered to electrode $\mathrm{C}$ induced a compound LTP consisting of both NMDALTP and vDCCLTP (Grover and Teyler 1995), averaging $175 \%$ of pretetanus baseline for the population spike (Fig. 3A). Electrodes A and E, located $200 \mu \mathrm{m}$ distal to the tetanized electrode, showed a significantly smaller potentiation of the population spike, averaging 119\% $(P<0.05)$.

A $50-\mathrm{Hz}$ tetanus in normal aCSF delivered to electrode $\mathrm{C}$ elicits only NMDALTP. This tetanus induced a nonsignificantly smaller LTP (163\%) than did the $200-\mathrm{Hz}$ tetanus at electrode $\mathrm{C}$ (cf. Fig. 4A to Fig. 3A, $P>0.12$ ). The electrodes distal to electrode $\mathrm{C}$ showed comparable potentiation (average of $156 \%$ ) of the population spike. The potentiation at electrodes $\mathrm{A}$ and $\mathrm{E}$ were not significantly different from electrode $\mathrm{C}(P>0.41)$. A perfusion of APV coupled with a $200-\mathrm{Hz}$ tetanus induces an isolated VDCCLTP (APV blocks the NMDA form). This procedure resulted in a $192 \%$ potentiation of
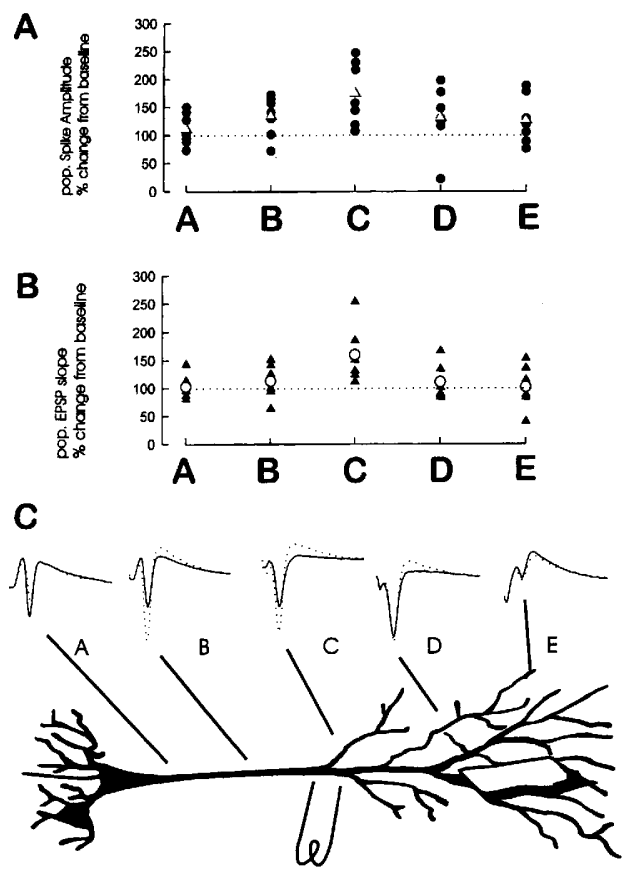

Figure 3: Results from slices given a $200-\mathrm{Hz}$ tetanus in normal aCSF. For each slice, population spike amplitude and EPSP slopes were calculated as percent change from baseline response at each electrode. (A) The individual data points of the population spike amplitude. $(\triangle)$ The mean of each electrode over all slices $(n=7)$. (B) The individual data points of the EPSP slopes; $(O)$ the mean of each electrode for all the slices. (C) Representative data from one experiment. Baseline responses are shown in solid lines, and the post-tetanus response is shown in dotted lines. The schematic of the pyramidal cell at the bottom shows the approximate locations of the electrodes.

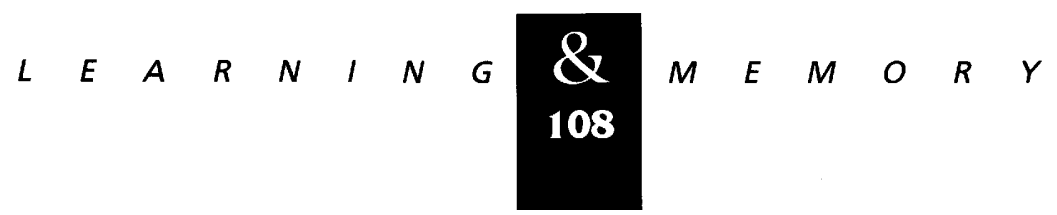




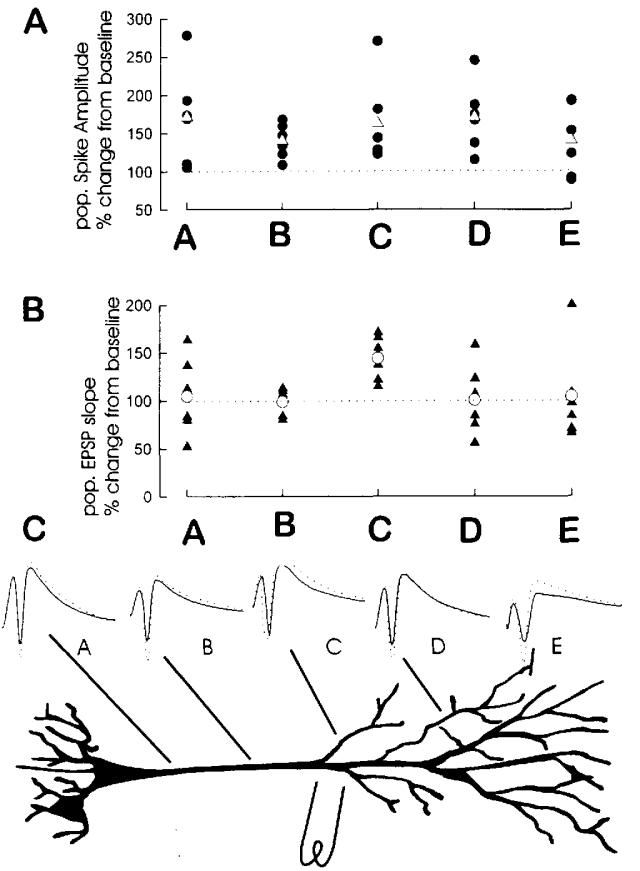

Figure 4: Results from slices given a $50-\mathrm{Hz}$ tetanus in normal aCSF. For each slice, population spike amplitude and EPSP slopes were calculated as percent change from baseline response. $(A)$ The individual data points of the population spike amplitude. $(\triangle)$ The mean over all slices at each electrode position $(n=6)$. (B) The individual data points of the EPSP slopes; $(O)$ the mean for each electrode. (C) Representative data from one experiment. Baseline responses are shown in solid lines, and the post-tetanus response is shown in dotted lines. The schematic of the pyramidal cell at the bottom shows the approximate locations of the electrodes.

the population spike amplitude (Fig. 6A, below) at electrode $\mathrm{C}$. The distal electrodes displayed no significant potentiation $(104 \%)$, indicating that this tetanus did not result in any synaptic change at the distal sites as compared with the tetanized site $(P<0.001)$.

In the presence of Nifedipine and a $200-\mathrm{Hz}$ tetanus, only NMDALTP is elicited (Nifedipine blocks VDCCLTP). Under these conditions the population spike elicited by the tetanized electrode potentiated by $207 \%$ (Fig. 6A, below), whereas the population spike elicited by the distal electrodes showed only a $111 \%$ change, barely above the definition of LTP.

\section{LTP—DISTAL SITES—PEPSP}

A $200-\mathrm{Hz}$ tetanus in normal media resulted in LTP $(160 \%$ of the pretetanus baseline pEPSP slope) at electrode C (Fig. 3B). However, distal electrodes $\mathrm{A}$ and $\mathrm{E}$ showed an average change in slope of $103 \%$, below our definition of synaptic plasticity. With a $50-\mathrm{Hz}$ tetanus, the pEPSP slope showed 145\% LTP (Fig. 4B) at electrode C. Unlike the distal population spike tetanized site, which potentiated, the average distal pEPSP slope was unchanged (at 104\%), with individual slices both showing increases and decreases $(P<0.01$ compared with electrode C).

Selectively induced vDCCLTP resulted in pEPSP potentiation (157\%) at electrode C (Fig. $5 \mathrm{~B}$, the average is elevated owing to an outlying data point) with a small depression ( $90 \%)$ at distal sites $(P<0.09)$. Selectively induced NMDALTP (at $200 \mathrm{~Hz}$ ) resulted in a small (125\%) potentiation of the pEPSP slope at electrode C (Fig. 6B). However, at distal electrodes $A$ and $E$, the pEPSP slope
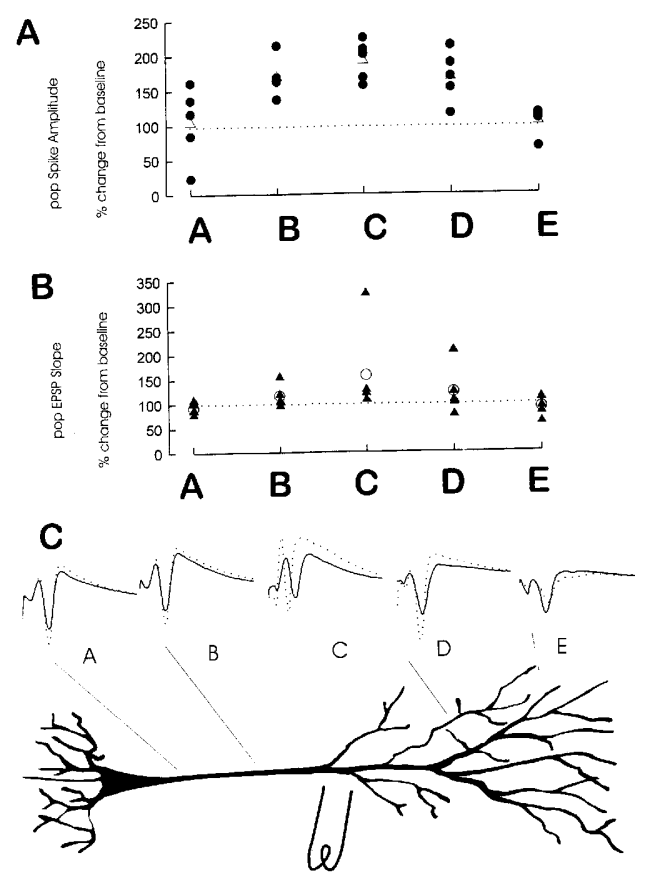

Figure 5: Results from slices given a $200-\mathrm{Hz}$ tetanus coupled with perfusion of APV. For each slice, population spike amplitude and pEPSP slopes were calculated as percent change from baseline response. $(A)$ The individual data points of the population spike amplitude. $(\triangle)$ The mean for each electrode position $(n=5)$. (B) The individual data points of the EPSP slopes; $(O)$ the mean for each electrode. (C) Representative data from one experiment. Baseline responses are shown in solid lines, and the post-tetanus response is shown in dotted lines. The schematic of the pyramidal cell at the bottom of the figure shows the approximate locations of the electrodes. 


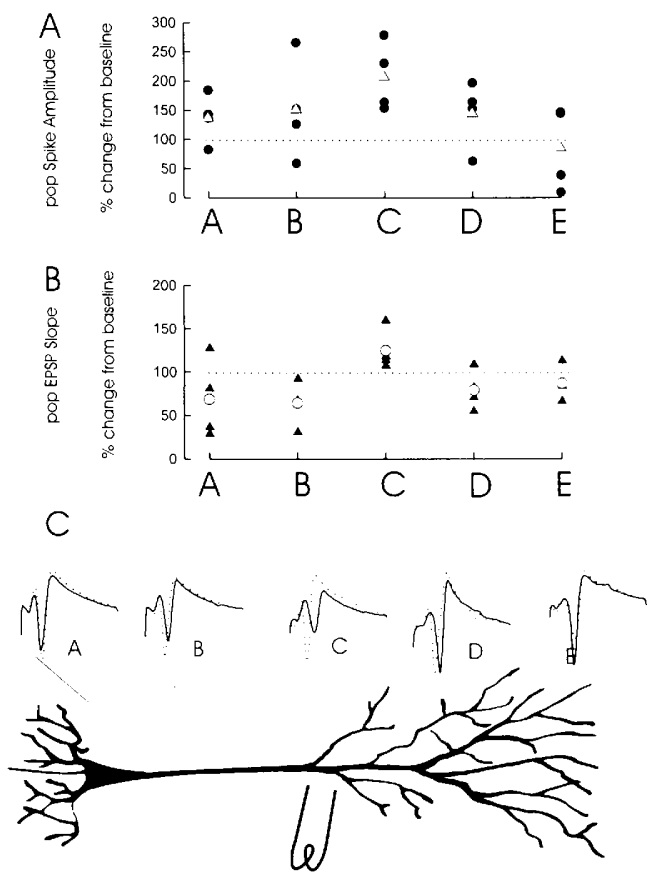

Figure 6: Results from slices given a $200-\mathrm{Hz}$ tetanus in the presence of Nifedipine. For each slice, population spike amplitude and EPSP slopes were calculated as percent change from baseline response. (A) The individual data points of the population spike amplitude. $(\triangle)$ The mean for each electrode position $(n=4)$. (B) The individual data points of the EPSP slopes; $(O)$ the mean for each electrode. (C) Representative data from one experiment. Baseline responses are shown in solid lines, and the post-tetanus response is shown in dotted lines. The schematic of the pyramidal cell at the bottom shows the approximate locations of the electrodes.

showed LTD averaging $78 \%(P<0.01$ as compared with electrode $\mathrm{C}$ ).

\section{LTP—PROXIMAL SITES}

Electrode sites at B and D were not independent of the tetanized electrode $\mathrm{C}$, in that one pole of each electrode was common. Because some percentage of fibers stimulated by electrode $B$ were also tetanized by electrode $\mathrm{C}$, it can be expected that these sites would yield results similar to electrode $\mathrm{C}$, but of lesser magnitude. This was generally true following NMDALTP, VDCCLTP induction (200-Hz tetanus; Fig. 4B), and VDCCLTP induction (200 Hz in APV; Fig. 5B). Statistical analysis showed no significant differences in the pEPSP slope and population spike amplitude between the proximal and electrode $\mathrm{C}$ for either group $(P>0.08)$.

\section{POPULATION EPSP/POPULATION SPIKE CORRELATIONS}

It might be expected that pEPSPs and population spikes should be correlated, as a potentiated pEPSP could be expected to inject more depolarizing current into the population of neurons, resulting in a larger population spike. Although the correlation between the pEPSP and population spike recorded at electrode $\mathrm{C}$ is positive for some conditions (Figs. 4 and 5), it is negative for others (Figs. 3 and 6), averaging a nonsignificant -0.19 across all conditions. A similar situation holds for the distal electrodes where the correlation is positive for some conditions (electrode A, Figs. 4 and 6; electrode E, Figs. 5 and 6), and negative for others (electrode A, Figs. 3 and 6; electrode E, Figs. 3 and 4), averaging a nonsignificant 0.21 overall. Thus, between pEPSP and population spike measures, there appears to be no relationship between the magnitude of pEPSP potentiation and the magnitude of population spike potentiation. Clearly, potentiation of the pEPSP is not the sole determinant of population spike potentiation. Whereas these are population measures, it is unlikely that consistent correlations would be apparent at the single cell level, somehow masked under the conditions of our experiment.

\section{Discussion}

The central finding from this experiment is that an LTP-inducing tetanus delivered to one dendritic site results in changes at adjacent nontetanized dendritic synapses. In this experiment the two proximal stimulation sites shared some fibers with the tetanized site and the two distal sites were independent of the tetanus site. Thus, we expected that the proximal sites would display a lower magnitude of LTP given the overlap in fibers. The distal electrode sites were independent of the fibers stimulated by electrode $\mathrm{C}$ and therefore would not be expected to show LTP following a tetanus delivered to electrode $\mathrm{C}$. The results generally confirmed our expectation that the distal sites would not display LTP (with the exception of the population spike NMDALTP induced in Figs. 4 
and 6) and that the proximal sites would display a smaller amount of LTP (with the exception ofthe pEPSPs of Fig. 6, which displayed LTD). Although LTP was not often seen at the distal sites, LTD was.

By what mechanism can synapses adjacent to (but independent from) a set of tetanized inputs become altered? Because these forms of synaptic plasticity are all induced by postsynaptic increases in cytosolic $\mathrm{Ca}^{2+}$ (Teyler et al. 1994), one possibility is that the $\mathrm{Ca}^{2+}$ entering via activated channels or released from intracellular stores at the tetanus site could diffuse to the other sites. Although possible, this is unlikely as the distance to the electrode sites $(100$ and $200 \mu \mathrm{m})$ is much longer than the ability of $\mathrm{Ca}^{2+}$ to freely diffuse before binding to the multiple calcium-binding proteins found in the cytosol [estimated at $0.1 \mu \mathrm{m}$ by Allbritton et al. (1992)]. Fura imaging studies suggest that the diffusion distance of intracellular $\mathrm{Ca}^{2+}$ is $\sim 10 \mu \mathrm{m}$ (Conner et al. 1993; Malinow et al. 1994); thus, $\mathrm{Ca}^{2+}$ diffusion between $0.1 \mu \mathrm{m}$ and $10 \mu \mathrm{m}$ cannot account for the changes observed at synapses $200 \mu \mathrm{m}$ from the tetanized synapses.

Although free calcium is unlikely to diffuse the distance required, activated calcium-binding proteins are capable of diffusing along the dendrite for relatively long distances (Allbritton et al. 1992). Major targets of tetanus-induced increased cytosolic $\mathrm{Ca}^{2+}$, whether from activated NMDA receptors, VDCC channels, or metabotropic glutamate receptor ( $\mathrm{mGluR}$ ) coupled to internal calcium stores, include protein kinases, protein phosphatases, and calmodulin (which in turn can activate calcium/calmodulin kinase II), all of which have been implicated in the expression of various forms of synaptic plasticity (Teyler et al. 1994). These activated enzymes may be capable of diffusing into adjacent regions of the dendrite to affect alterations in synaptic efficacy at nontetanized sites. Another possibility is that voltage-dependent $\mathrm{Na}^{+}$conductances known to invade regions of a dendrite may stimulate $\mathrm{Ca}^{2+}$ entry and calciumbinding protein activation in these regions (Jaffe et al. 1992). The recent observation that mGluR activation induces a $\mathrm{Ca}^{2+}$-dependent release of $\mathrm{Ca}^{2+}$ (calcium waves) within hippocampal dendrites, provides an alternative mechanism for the liberation of free calcium at remote dendritic sites (Jaffe and Brown 1994). Because mGluRs are activated during tetani (Bashir et al. 1993) and $\mathrm{Ca}^{2+}$ is released from endoplasmic reticulum stores, this source of free $\mathrm{Ca}^{2+}$ may be involved in activating the calcium-binding proteins responsible for synaptic plasticity seen at distal dendritic sites. As mGluR antagonists were not used in this study, such a possibility cannot be ruled out. Thus, both diffusing $\mathrm{Ca}^{2+}$-binding proteins and calcium waves are potential candidates underlying the heterosynaptic plasticity observed here.

If $\mathrm{Ca}^{2+}$ is made available at adjacent sites, by what mechanism could different forms of synaptic plasticity, for example, LTD, be expressed? The induction of LTP versus LTD is a function either of level of depolarization (Collingridge and Singer 1985 ), the postsynaptic $\mathrm{Ca}^{2+}$ concentration (Lisman 1989; Artola and Singer 1993), or local changes in $\mathrm{Ca}^{2+}$ concentration (compartmentalization; Teyler et al. 1994). These differences in cytosolic $\mathrm{Ca}^{2+}$ are proposed to act on calciumbinding proteins that differ in cytosolic location and $\mathrm{Ca}^{2+}$ binding affinity. The differentially activated calcium-binding proteins would then be responsible for different forms of synaptic plasticity. A number of kinases have been implicated in the induction and maintenance of NMDALTP, including the serine-threonine kinases calcium/calmodulin kinase II (CaMKII; Reymann et al. 1988), protein kinase C (PKC; Huang et al. 1992), protein kinase A (PKA; Matthies and Reymann 1993), and tyrosine kinases (O'Dell et al. 1991). The broadspectrum serine-threonine kinase inhibitor $\mathrm{H}-7$ is able to block the maintenance phase of NMDALTP but not VDCCLTP (Grover and Teyler 1995). Conversely, the broad-spectrum tyrosine kinase inhibitors genistein and lavendustin $\mathrm{A}$ are able to selectively block vDCCLTP but not NMDALTP (Cavus and Teyler 1996). At moderate levels of postsynaptic activation and thus cytosolic $\mathrm{Ca}^{2+}$, NMDALTP is induced. At higher levels of activation, VDCCLTP is brought into play and is coexpressed along with NMDALTP (Cavus and Teyler 1996).

LTD is induced by low-frequency stimulation that presumably results in smaller increases in intracellular calcium. Mulkey and Malenka (1992) blocked LTD in area CA1 with an NMDA antagonist, showing that LTD is mediated via NMDA receptors. These authors also demonstrated a critical role for protein phosphatases $1,2 \mathrm{~A}$, and $2 \mathrm{~B}$ (calcineurin) in the induction of LTD (Mulkey et al. 1993, 1994), suggesting that low levels of calcium influx activates phosphatases that participate in the dephosphorylation of their phosphoprotein substrates (Bear and Malenka 1994). Thus, we hypothesize that distal sites were exposed to lower

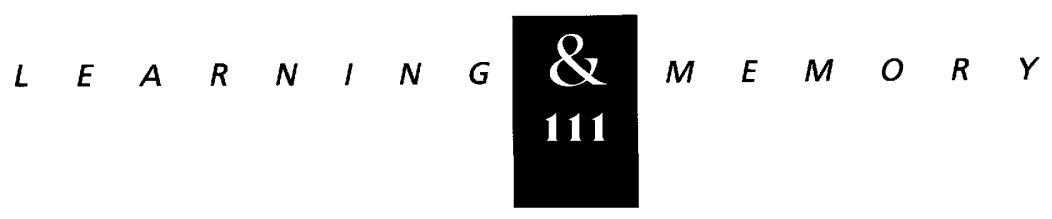


levels of cytosolic $\mathrm{Ca}^{2+}$, often resulting in the induction of LTD via phosphatase activation. The proximal sites, which did not show LTD, demonstrated lower levels of LTP. We suggest that two factors are responsible for the synaptic plasticity seen at proximal sites: homosynaptic LTP caused by stimulation of overlapping fibers and heterosynaptic LTP triggered by local increases in cytosolic $\mathrm{Ca}^{2+}$-binding protein and/or calcium waves.

Proximal sites showed a smaller LTP magnitude than the tetanized electrode (attributable to sharing of afferent fibers by the electrodes) with two exceptions (see Figs. 4 and 6). In these exceptions the pEPSP either showed no change (Fig. 4) or showed LTD (Fig. 6). In Figure 4, a 50-Hz tetanus was used to selectively activate NMDA receptors, whereas in Figure 6, the dihydropyridine VDCC antagonist Nifedipine was used to antagonize the VDCC component of LTP induced by a $200-\mathrm{Hz}$ tetanus. Thus, in both cases the tetanus was induced via NMDA receptor activation. In contrast to VDCC activation, NMDA receptor activation presumably admits less $\mathrm{Ca}^{2+}$ to the postsynaptic cell, resulting in less diffusion of $\mathrm{Ca}^{2+}$ or its binding proteins (Teyler et al. 1994). A lower level of $\mathrm{Ca}^{2+}$ at adjacent synapses would be expected to result in LTD. In the proximal synapse experiments in which VDCCs were activated, the higher $\mathrm{Ca}^{2+}$ fluxes induced modest magnitudes of LTP.

Across most experiments, the spread of potentiation was greater for the population spike measure of LTP than for the pEPSP measure. Another way of stating this is that there was an EPSP-spike (E-S) dissociation at the nontetanized sites. Inspection of Figures $4-6$ shows that, on average, both proximal and distal population spikes were potentiated at the same time that the corresponding pEPSPs were at or below baseline. This result reveals that the population spike is influenced by factors other than the local current associated with the pEPSP. This dissociation was not limited to the nontetanized sites, as there was no correlation between EPSP potentiation and spike potentiation for any site. The most obvious extrasynaptic influence on the plasticity of these cells is the level of inhibitory influence they experience. Because, on average, the spike was potentiated in the absence of EPSP potentiation, one likely possibility is that the inhibitory drive on these tetanized cells is reduced. The mechanism underlying E-S potentiation is thought to be different than that under- lying synaptic potentiation. Abraham et al. (1985) found no correlation between the magnitude of synaptic and E-S potentiation, $r=0.23$. This is comparable to the correlations reported here. Although input specificity has been shown for synaptic LTP, Abraham and colleagues (1985) reported heterosynaptic changes in the dentate gyrus, as do we in CA1. They suggest that the changes are attributable to changes in postsynaptic excitability. Others have suggested that there is a reduction in the synaptic inhibition/excitability ratio. The result would be a reduction in threshold necessary for neuronal discharge (Chavez-Noriega et al. 1990).

The effects of tetanic stimulation were more variable than expected at distal sites. Under conditions producing consistent LTP at electrode C (e.g., Fig. 4), the distal sites displayed a range of effects ranging from LTP to LTD. What could account for variability at the distal sites? Clearly the potentiated synapses are subjected to conditions to which the nontetanized synapses are not exposed. The tetanus exposes terminals to a sudden and significant release of transmitter and exposes the dendritic spine to a large depolarization, calcium influx, and activation of many calcium-binding proteins, little of which directly affects the distal synapses. The large depolarization affects the tetanized synapses in ways other than triggering LTP. Robinson et al. (1991) have shown, for example, that the establishment of LTP reduces variability significantly at potentiated synapses, suggesting that the variability seen distally reflects more accurately the nature of naive synapses. The variability may reflect the differences in local conditions at naive synapses not exposed to the compelling influence of a tetanus, the plasticity history of these synapses, variations in the subunit composition of AMPA receptors (Nusser et al. 1994), and variations in the $\mathrm{Ca}^{2+}$ conductance of ion channels (Malinow et al. 1994). A similar heterogeneity of synaptic plasticity was seen by Malgaroli et al. (1995) in a study of synaptic vesicle recycling during LTP. They interpreted this heterogeneity as reflecting the recent activation history of the synapses. Given the differing synaptic activation histories of distal synapses, the influence of a remote tetanus and its associated $\mathrm{Ca}^{2+}$ influx might be to induce LTP in synapses of high basal activity and LTD in synapses of low basal activity. Thus, instances of LTD at distal synapses may reflect the functional history of the synapse as opposed to differences in cytosolic calcium levels. 
These alternatives cannot be differentiated in the present experiment.

\section{Acknowledgments}

This work was conducted in partial fulfillment of the Ph.D. requirements for C.M.C. and was supported in part by National Institutes of Health grant NS28698.

The publication costs of this article were defrayed in part by payment of page charges. This article must therefore be hereby marked "advertisement" in accordance with 18 USC section 1734 solely to indicate this fact.

\section{References}

Abraham, W.C. and G.V. Goddard. 1983. Asymmetric relationships between homosynaptic long-term potentiation and heterosynaptic long-term depression. Nature 305: 717-719.

Abraham, W.C. and J.R. Wickens. 1991. Heterosynaptic long-term depression is facilitated by blockade of inhibition in area CA1 of the hippocampus. Brain Res. 546: 336-340.

Abraham, W.C., T.V.P. Bliss, and G.V. Goddard. 1985. Heterosynaptic changes accompany long-term but not short-term potentiation of the perforant path in the anaesthetized rat. J. Physiol. 363: 335-349.

Allbritton, N.L., T. Meyer, and L. Stryer. 1992. Range of messenger action of calcium on inositol 1,4,5-triphosphate. Science 258: 1812-1815.

Artola, A. and W. Singer. 1993. Long-term depression of excitatory synaptic transmission and its relationship to long-term potentiation. Trends Neurosci. 16: 480-487.

Bashir, Z.I., Z.A. Bortollotto, C.H. Davies, N. Berretta, A.J. Irving, A.J. Seal, J.M. Henley, D.E. Jane, J.C. Watkins, and G.L. Collingridge. 1993. Induction of LTP in the hippocampus needs synaptic activation of glutamate metabotropic receptors. Nature 33: 347-350.

Bear, M.F. and R.C. Malenka. 1994. Synaptic plasticity: LTP and LTD. Curr. Opin. Neurobiol. 4: 389-399.

Borroni, A., F. Chen, N. LeCursi, L.M. Grover, and T.J. Teyler. 1991. An integrated multielectrode electrophysiological system. J. Neurosci. Meth. 36: 177-184.

Cavus, I. and T. Teyler. 1996. Two forms of long-term potentiation in area CA1 activate different signal transduction cascades. J. Neurophysiol. (in press).

Chavez-Noriega, L.E., J.V. Halliwell, and T.V.P. Bliss. 1990. A decrease in firing threshold after induction of the EPSP-spike (E-S) component of long-term potentiation in rat hippocampal slices. Exp. Brain Res. 79: 633-641.

Collingridge, G.L. and W. Singer. 1985. Excitatory amino acid receptors and synaptic plasticity. Trends Pharmacol. Sci. 11: 290-296.
Conner, J.A., L.D.P. Miller, J. Petrozzino, and W. Muller. 1993. Calcium signaling in dendritic spines of hippocampal neurons. J. Neurobiol. 25: 234-242.

Grover, L.M. and T.J. Teyler. 1994. Different mechanisms are required for maintenance of NMDA receptor dependent and independent LTP. Synapse 19: 121-133.

Huang, Y.Y., P.A. Colley, and A. Routtenberg. 1992. Postsynaptic then presynaptic protein kinase $C$ activity may be necessary for long-term potentiation. Neuroscience 49: 819-827.

Jaffe, D.B. and T.H. Brown. 1994. Metabotropic glutamate receptor activation induces calcium waves within hippocampal dendrites. J. Neurophysiol. 72: 471-474.

Jaffe, D.B., D. Johnston, N. Lasser-Ross, J.E. Lisman, H. Miyakawa, and W.N. Ross. 1992. The spread of $\mathrm{Na}+$ spikes determines the pattern of dendritic $\mathrm{Ca}^{2+}$ entry into hippocampal neurons. Nature 357: 244-246.

Lisman, J. 1989. A mechanism for the Hebb and the anti-Hebb processes underlying learning and memory. Proc. Natl. Acad. Sci. 86: 9574-9578.

Malgaroli, A., A.E. Ting, B. Wendland, A. Bergamaschi, A. Villa, R.W. Tsiem, and R.H. Scheller. 1995. Presynaptic component of long-term potentiation visualized at individual hippocampal synapses. Science 268: 1624-1628.

Malinow, R., N. Otmakhov, K.I. Blum, and J. Lisman. 1994. Visualizing hippocampal synaptic function by optical detection of $\mathrm{Ca}^{2+}$ entry through the $\mathrm{N}$-methyl-D-aspartate channel. Proc. Natl. Acad. Sci. 91: 8170-8174.

Matthies, H. and K.G. Reymann. 1993. Protein kinase A inhibitors prevent the maintenance of hippocampal long-term potentiation. NeuroReport 4: 712-714.

Mulkey, R.M. and R.C. Malenka. 1992. Mechanisms underlying induction of homosynaptic long-term depression in area CA1 of the hippocampus. Neuron 9: 967-975.

Mulkey, R.M., C.E. Herron, and R.C. Malenka. 1993. An essential role for protein phosphatases in hippocampal long-term depression. Science 261: 1051-1055.

Mulkey, R.M., S. Endo, S. Shenolikar, and R.C. Malenka. 1994. Involvement of a calciunerin/inhibitor-1 phosphatase cascade in hippocampal long-term depression. Nature 369: 486-488.

Nusser, Z., E. Mulvihill, P. Streit, and P. Somogyi. 1994. Subsynaptic segregation of metabotropic and ionotropic glutamate receptors as revealed by immunogold localization. Neuroscience 61: 421-427.

O'Dell, T.J., E.R. Kandel, and S.G. Grant. 1991. Long-term potentiation in the hippocampus is blocked by tyrosine kinase inhibitors. Nature 353: 558-560.

Reymann, K.G., R. Brodemann, H. Kase, and H. Matthies.

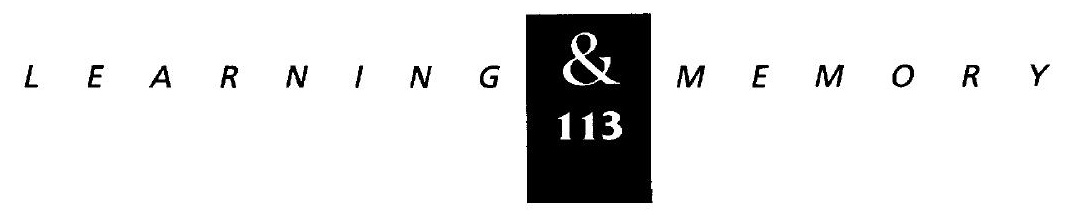




\section{Coussens and Teyler}

1988. Inhibitors of calmodulin and protein kinase $C$ block different phases of hippocampal long-term potentiation. Brain Res. 461: 388-392.

Robinson, G.B., R.J. Sclabassi, and T.W. Berger. 1991. Kindling-induced potentiation of excitatory and inhibitory inputs to hippocampal dentate granule cells. I. Effects on linear and non-linear response characteristics. Brain Res. 562: 17-25.

Teyler, T.J. 1980. Brain slice preparation: Hippocampus. Brain Res. Bull. 5: 391-403.

Teyler, T.J., I. Cavus, C. Coussens, P. DiScenna, L. Grover, Y.P. Lee, and Z. Little. 1994. Multideterminant role of calcium in hippocampal synaptic plasticity. Hippocampus 4: $61-634$.

Received June 17, 1996; accepted in revised form August 29, 1996. 


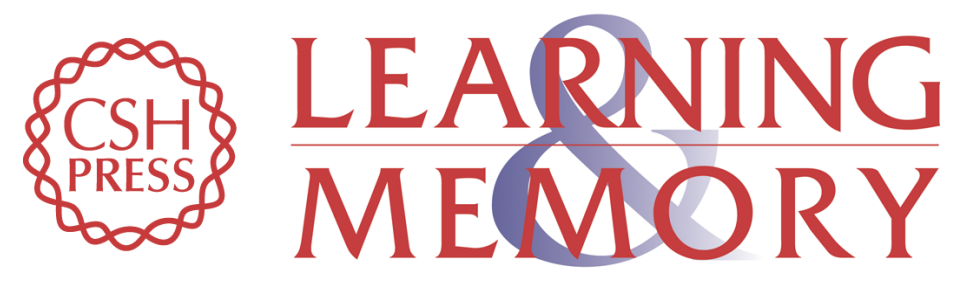

\section{Long-term potentiation induces synaptic plasticity at nontetanized adjacent synapses.}

C M Coussens and T J Teyler

Learn. Mem. 1996, 3:

References This article cites 28 articles, 5 of which can be accessed free at: http://learnmem.cshlp.org/content/3/2-3/106.full.html\#ref-list-1

License

Email Alerting

Receive free email alerts when new articles cite this article - sign up in the box at the Service top right corner of the article or click here. 